\title{
Folato Sérico y Eritrocitario en el Lactante: Influencia de la Nutrición de Hierro
}

\author{
Dr. Manuel Olivares G.; T.M. Mary Anderson.; T.M. Sandra Llaguno A.; \\ T.M. Patricia Chadud M.; Dr, Abraham Stekel G. ${ }^{1}$

\section{Serum and Erythrocyte Folate in Infancy: Effect of Iron Nutrition Status}

\begin{abstract}
Term infants, were examined at $9(n=215)$ and $15(n=198)$ months of age for levels of serum and red cell folate, hemoglobin, serum iron, total iron binding capacity, free erythrocyte protoporphyrin and serum ferritin. Mean ery throcyte folate levels were consistently higher $(p<0,005)$ in iron deficient anemic infants. No diferences were noted in serum folate tevels. These results suggest, assuming similar intakes of folate, that folate stores depend on the sufficiency of iron nutrition. Iron deficient erythropoieses determines less utilization of folate stores.
\end{abstract}

(Key words: Folate deficiency, serum, ery throcy te. Iron deficiency).

Los países en vías de desarrollo presentan una alta prevalencia de anemias nutricionales. En ocasiones esta anemia se debe a una deficiencia combinada de hierro y folato ${ }^{1}$.

Para la evaluación de la nutrición de ácido fólico, se utiliza la determinación de las concentraciones de folato sérico y eritrocitario. Existe en la literatura información contrađictoria sobre el efecto de la nutrición de hierro sobre los niveles sanguíneos de esta vitamina. El propósito del presente trabajo fue el de contribuji al esclarecimiento de esta relación.

\section{MATERIAL Y METODOS}

Se estudió un grupo de lactantes sanos, de tétmino, provenientes de un estrato de bajo nivel socioeconómi$\infty$, de los consultorios San Joaquín y La Reina de las áreas sur y oriente de Santiago. Previn autorización de

1. Unidad de Hematologia, Instituto de Nutrición y Tecnología de los Alimentos, Universidad de Chile. los padres, se obtuvo en ayunas una muestra de sangre venosa, determinándose en 215 lactantes de 9 meses de edad y en 198 de 15 mesess, los sigujentes exámenes de laboratorio: concentración de hemoglobina ${ }^{2}$, hierro sérico, capacidad total de combinación de hierro y saturación de la transferrina ${ }^{3}$, protoporfirina libre eritrocitaria ${ }^{4}$, ferritina sérica ${ }^{5}$, folato sérico y eitrocitario, mediante un ensayo biológico con lactobacillus casej6,7.

Dado el hecho de que los valores de ácido fólico presentan una distribución asimśtrica, la que se normaliza al efectuar una transformación logarítmica, los resultados se expresaron como promedios geométricos ${ }^{8}$.

Como límftes de normalidad de los parámetros de laboratorio indicadores de la nutrición de hierro se utilizaron los siguientes criterios: hemoglobina $11 \mathrm{~g} \mathrm{x}$ $\mathrm{dr}^{9}$, saturación de la transferrina $9 \% 10$ protoporfitina libre eritrocitaria 120 ug $x$ dl GR a los 9 meses y 100 ug $x$ dl GR a los 15 meses 10 y ferritina sérica 10 ug $x]^{11}$.

Basándose en estos límites, los lactantes fueron divididos en: normales (todos los parámetros normales); sideropénicos no anémicos (hemoglobina normal y uno, dos o más parámetros alterados); anémicos ferroprivos (hemoglobina bajo lo normal y 1 ó más parámetros altetados).

En el análisis estadístico se utilizó la prueba " $t$ " de Student. 


\section{RESULTADOS}

El estado de nutrición de hierro no tuvo intluencia sobre los niveles séricos de ácido fólico, aunque los sujetos anémicos ferroprivos presentaron valores de folato sérico más altos que los normales, diferencia que no fue estadistica. mente significativa (Tabla 1 ).

Los lactantes anémicos (Tabla 2), tuvieron concentraciones de folato eritrocitario significatiłamente más altas que las normales $(\mathrm{p}<0,005)$. Los niños sideropénicos no anémi$\cos$ no difirieron de los normales en sus concentraciones de folato eritrocitario.

Tabla 1

Folato sérico (ug/l) en lactantes normales $y$ deficientes en hierro*

\begin{tabular}{lcc}
\hline Edad (meses) & 9 & 15 \\
\hline \multirow{3}{*}{ Normales } & 12,7 & 13,7 \\
& $6,6-24,3$ & $8,2-22,9$ \\
& $\mathrm{~N}=136$ & $\mathrm{~N}=121$
\end{tabular}

Siderepénicos

\begin{tabular}{|c|c|c|}
\hline $\begin{array}{l}1 \text { parámetro } \\
\text { alterado }\end{array}$ & $\begin{array}{c}12,4 \\
5,9-25,9 \\
N=40\end{array}$ & $\begin{array}{c}13,1 \\
7,6-22,8 \\
N=39\end{array}$ \\
\hline $\begin{array}{l}2 \text { ó más } \\
\text { parámetros } \\
\text { alterados }\end{array}$ & $\begin{array}{c}11,6 \\
5,7-23,4 \\
N=12\end{array}$ & $\begin{array}{c}15: 1 \\
9,5-23,9 \\
N=14\end{array}$ \\
\hline $\begin{array}{l}\text { Anémicos } \\
\text { ferroprivos }\end{array}$ & $\begin{array}{c}13,9 \\
6,6-29,2 \\
\mathrm{~N}=27\end{array}$ & $\begin{array}{c}15,3 \\
7,4-31,5 \\
N=24\end{array}$ \\
\hline
\end{tabular}

*Promedio geométrico y rango de l desviación estindar. $\mathrm{N}=$ número de casos.

Tabla 2.

Folato eritrocitario (ug// GR) en lactantes normales $y$ deficientes en hierro*

\begin{tabular}{lcc}
\hline Edad (meses) & 9 & 15 \\
\hline \multirow{2}{*}{ Notmales } & 301 & 355 \\
& $194-\mathbf{4 6 6}$ & $235-537$ \\
$\mathrm{~N}=136$ & $\mathrm{~N}=121$
\end{tabular}

Sideropénicos

$\begin{array}{lcc}1 \text { parámetro } & 319 & 344 \\ \text { alterado } & 182-558 & 221=536 \\ & \mathrm{~N}=40 & \mathrm{~N}=39 \\ & 302 & 357 \\ 2 \text { ó más } & 183-498 & 240-531 \\ \text { parámetros } & \mathrm{N}=12 & \mathrm{~N}=13 \\ \text { altcrados } & 429 * * & 468 * \\ \text { Anémicos } & 248-741 & 309-710 \\ \text { ferroprivos } & \mathrm{N}=27 & \mathrm{~N}=24 \\ \end{array}$

* Promedio geométrico y rango de 1 desviación estándar. $\mathrm{N}=$ núnera de casos.

${ }^{* *} \mathrm{p}<0,005$ ver sus normales

\section{DISCUSION}

Se conoce bastante poco el efecto de la deficiencia de hierro sobre el metabolismo de] acido fólico. La información existente es contradictoria.

En la deficiencia de hierro se han descrito cambios megaloblásticos en la medula ósea, hipersegmentación de los neutrófilos y aumento de la excreción urinaria de acjdo formimino glutámico (Figlu) ${ }^{12-\text { I } 5}$, hallazgos que han sido atribuidos a deficiencia secundaria de ácido fólico. Estas modificaciones se revierten después de terapia con hierro.12-15 Vitale y col.15 encontraron que ratas deficientes en hierro presentaban disminución de la actividad de la enzima glutamato formimino transferasa hepática, que participa en la transferencia del grupo formímino al ácido tetrahidrofólico. En un estudio posterior realizado también en ratas, no se demostraron alteraciones de esta enzima 16 .

La interpretación de los estudios anteriormen. te sefralados es difícil, por falta de grupos contro. les adecuados o tratarse de deficiencias mixtas de hierro y folato. Estudios metabólicos en sujetos con defíciencia de hierro no complicada, han concluido que no existe una verdadera deficiencja de ácido fólico en esta condición ${ }^{14}$.

En la carencia de hierro se had descrito disninución de la concentración de folato sérico en el hombre ${ }^{17}$ y en ratas ${ }^{15,18}$. Otros autores no han encontrado modificaciones de las concentraciones séricas $14,19,20$, lo que coincide con nuestros hallazgos. La variabilidad de estos resultados puede atribuirse al hecho conocido, que la concentración sérica de ácido fólico se correlaciona mejor con la ingesta de las últimas semanas, mientras que el contenido intraeritrocitario lo hace con la concentración tisular de la vitamina.

Bastante más consistente es la constatación de concentraciones eritrocitarias de folato elevados en sujetos deficientes en hierro1, 14, 19, 20 lo que coincide plenamente con to encontrado en nuest ro estudio.

Estas modificaciones en los niveles sanguineos se han descrito en sujetos anémicos ferroprivos. Nuestros resultados concuerdan con esto, demostrando que estas anomalias no están presentes en los sujetos deficientes en hierro no anémicos.

Se ha descrito que la terapia con hierro produce aumento ${ }^{18,19}$, disminución 14 o no modifica los niveles sêricos de ácido fólicol 2,20. La concentración intraeritrocitaria se reduce después de una terapia con hierro $14,19,20$.

En ratas con deficiencia de hierro se ha demostrado que no existe alteración de la absorción del ácido fólico, cambios en la flora intestinal a secuestro de folato por estos microorganismos 
intestinales 18 . Por estas razones, inicialmente las alteraciones de los niveles de folato séricos se atribuyeron a un posible atrapamiento hepático del ácido fólico, con el consigujente impedimen. to del paso de este a la circulación, lo que se revertiría con la terapia con hierro 17 . Estas anomalías también se han pretendido explicar como consecuencia de un aumento de los requerimientos de ácido fólico en la deficiencia de hierro ${ }^{18}$. Estas hipótesis no son concordantes con el aumento de los njveles eritrocitarios de folato. La explicación más plausible es que al existir una limitación de la eritropoyesis, existe menor utilización de las reservas de ácido fólico, lo que determina aumento de la concentración eritrocitaria de la vitamina. Al corregir la deficiencia de hierro, el aumento de la velocidad de ta eritropoyesis lleva a mayor utilización del folato, con la consiguiente disminución de su concentración intraeritrocitaria.

La interrelación entre nutrición de hierro y ácido fólico, se debe tener presente al estudiar la nutrición de folato en poblaciones con una alta prevalencia de anemia ferropriva. No considerar este antecedente puede hacer subestimar la prevalencia de la escasez de ácido fólico.

\section{RESUMEN}

Se midieron, en un grupo de lactantes de término, las concentraciones de folato sérico y eritrocitario, hemoglobina, capacidad total de combinación de hierro, protoporfirina libre eritrocitaria y ferritina sérica a los 9 meses $(n=215)$ y 15 meses de edad $(n=198)$. Los lactantes anémicos ferroprivos presentaron un promedio de folato eritrocitario significativamente más alto $(\mathrm{p}<0,005)$ que los sujetos normales. No se apreciaron diferencias en las concentraciones de folato sérico. Estos resultados sugieren que, a igual aporte de ácido fólico, las reservas de folato dependen de la adecuación de la nutrición de hierro. Una eritropoyesis deficiente en hierro determinaría menor utilización de los depósitos de àcido fólico.

\section{REFERENCIAS}

1. Margo G., Baroni Y., Green R., Metz J.: Anemia in urban underprivleged children. lron, folate, and vitamin $B_{12}$ nutrition. Am. J. Clin. Nutr. 30: 947 , 1977.

2. International Committee for Standardization in Haematology:: Recommendatjons and requirements for haemoglobinometry in human blood. J. Clin. Path. 18: 353, 1965.
3. Fischer D.S., Price D.C.: A simple serum tron method using the new sensitive chromogen trypiridil-s-triazine. Clin. Chem. 10: 21, 1964.

4. Heller, S.R., Labbe R.F., Nutter, J.A.: A simplified assay for porphyryns in whole blood. Clin. Chem. 17: 528,1971 .

5. Gamma Dab ( 125 l] ferritin radiointmunoassay kit.: Clinical Assays Division of Travenol Lab. inc., Cambridge, Mass., USA.

6. Waters A.H., Mollin D.L. Studies on the folic acid activity of human serum. J. Clin. Path 14: 355, 1961.

7. Hoffrand A.V., Neweombe, B.F.A.: Mollin D.L.. Method of assay of red cell folate activity and the value of the assay as a test for folate deficiency. J. Сliл. Path. 19: 17, 1966.

8. Weil $A_{*}$, Mauracher $E_{*}$ : Folic acid and pregnancy: is there a real problem?. Schwerz. Med. Wschr. 107: $1943,1977$.

9. Report of WHO Group of Experts.: Nutrition anaemias. WHO. Tech. Rep. Serv. 503, 1972.

10. Rios E., Olivares $M$, A mar $M$. , Chadud P., Pizarro $F$., Stekel $A .:$ Evaluation of iron status and provalence of iron deficiency in infants in Chile. In: Nutrition Intervention Strategies in National Development. Underwood B.A. ed. New York, Academic Psess, 1983

11. Dallman P.R., Reeves, J.D.: Laboratory diagnosis of iron deficiency. In: Ion Nutrition in Infancy and Childhood. Stekel A., ed. Now York, Raven Press, 1984.

12. Velez H., Restrepo A, Vitale J,J, Hellerstein E.C. Folic acid deficiency secondary to iron deficiency in man. Remission with iron therapy and a diet low in folic acid. Am. J. Clin. Nutr. 19: 27, 1966.

13. Chonarin l., Rothman D., Berry V.: Iron deficiency and its relation to folic-acid status in pregnancy: results of a clinical trial. Brit. Med. J. 1 : $480,1965$.

14. Roberts P.D., St John D.J.B., Sinha R., Stewart J.S., Barti I.M, Coghill N.F., Morgan J.O.: Apparent folate deficiency in iron-deficiency anaemia. Brit. J. Haematol. 20: 165, 1971

15. Vitole J.J., Restrepo A., Velez A., Riker J.B., Hellerstein, E.C.: Secondary folate deficiency induced in the rat by dietary iron deficiency. $J$. Nutr. 88: 315, 1966.

16. Burns D.G., Spray G.H.: Normal folic acid metabolism in iron-defjicient tates. Brit. J. Nutr. 23: $665,1969$.

17. Saraya A,K., Tandon B.N, Ramachandran K.: Folic acid deficiency: effects of iron deficiency on serum folic acid Jevels. Indian J. Med. Res. 59: 1796, 1971.

18. Toskes Ph. P, Smith G,W., Bensinger T.A., Giannello R.A., Conrad M.E.: Folic acid abnormalities in iron deficiency: The mechanism of decreased serum folate levels in rats. Am, J, Clin, Nutt, 27: 355, 1974.

19. Omer A., Finlayson N.D.C., Shearman D.J.C., Samson R.R., Girwood R.H.: Plasma and erythrocyte folate in iron deficiency and folate deficiency. Blood 35: 821, 1970.

20. Sarayg A.K., Chaudhry V.P., Ghoi O.P.: Intertelationships of vitamin $B_{12}$, folic acid, and iron in anemia of infancy and childhood: effect of vitamin $B_{12}$ and iron therapy on folate metabolism. Am. J. Clin Nutr. 26: 640, 1973. 